\title{
sciendo
}

Current Issues in Pharmacy and Medical Sciences

Formerly ANNALES UNIVERSITATIS MARIAE CURIE-SKLODOWSKA, SECTIO DDD, PHARMACIA

journal homepage: http://www.curipms.umlub.pl/

\section{Comparative characteristics of proton pump inhibitor effectiveness in the treatment of gastric ulcer and duodenal ulcer}

\author{
Olesya P. Balitska*® ${ }^{\star}$, Tamara A. Germanyuk $\bullet$, Yuliia M. Hryhoruk $\odot$, \\ Tatiana I. Ivko®, Yulita O. Tomashevska $\bullet$, Vasyl M. Koval $\bullet$, Yuliia M. Polishchuk $\bullet$, \\ Viktoriia V. Hutsol ${ }^{\circledR}$, Myhailo A. Artemchuk ${ }^{\circ}$
}

Department of Pharmacy, National Pirogov Memorial Medical University, Vinnytsya, Ukraine

\section{ARTICLE INFO}

Received 11 April 2019

Accepted 27 July 2019

\section{Keywords:}

antidepressant,

peptic ulcer,

proton pump inhibitors,

efficiency.

\begin{abstract}
Aim. The aim of this study is to evaluate the efficiency of proton pump inhibitors in the treatment of gastric and duodenal ulcers as based on literature.

Materials and methods: The materials of this research are the results of 86 original studies on the effectiveness of proton pump inhibitors analysis.

Methods. Descriptive, statistical, retrospective.

Results and Conclusion. According to the clinical random researches, Omeprazole preparations are not included in the list due to proven better effectiveness of Esomeprazole drugs. Moreover, lansoprazole drugs are not included according to proven short-acid inhibitory effect. In addition, the brand of mentioned above preparation does not exist on the pharmaceutical market of Ukraine. Furthermore, rabeprazole preparations are presented in the research by Pariet (brand) and by the effective generic Barol, while pantoprazole preparations are represented in the research by Kontrolok (brand) and by the generic Pultset, as well as by Nolpaza. Herein, the Pantosan effect was not significantly different from the effect of Pultset and Nolpaza, but the preparation is much more expensive. In terms of efficiency (\%), 4 week repair of mucosal defects was carried out by way of the following treatment regimens: Barol + Amoxicillin + Clarythromycin

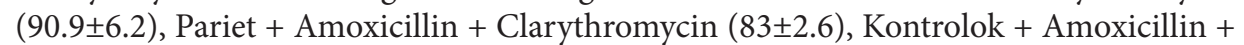

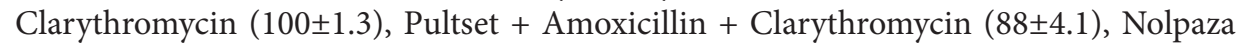
+ Amoxicillin + Clarythromycin (72 \pm 4.1$)$, Ezolonh + Amoxicillin + Clarythromycin (87.7 \pm 3.8$),$ Neksium + Amoxicillin + Clarythromycin (96.1 \pm 3.1$)$.
\end{abstract}

\section{INTRODUCTION}

\begin{abstract}
He who neglects all that justifies itself, and wants to lead researches different to that of others, deludes himself and deceives others.
\end{abstract}

Hippocrates

High morbidity, frequent relapses, long unserviceability of sick patients, significant economic losses - all of this allows the attribution of most urgent to the problem of stomach ulcer (SU) in modern medical practice. Herein, the inhibitors of proton pump (PPIs) show a high efficiency and

\footnotetext{
* Corresponding author

e-mail: olesyaba1984@gmail.com
}

safety in treating acid-dependent diseases (ADD). However, researches of efficiency in this area have not ceased. Hence, the purpose of this publication is a listing of data submission of comparative efficiency of PPIs in ADD treatment, based on the results of multicentre study.

About 30 years have passed since the beginning of research of medicaments which lower gastric secretion by blocking the $\mathrm{H}+/ \mathrm{K}+$ AT phase. Due to this, anticholinergic drugs and $\mathrm{H} 2$ histamine antagonists, now practically entirely removed from pharmaceutical market, were substituted by such pills as Omeprazole, Lansoprazole, Pantoprazole, Esomeprazole, Rabeprazole, all of which are ascribed as being inhibitors of proton pump (PPIs). 
Stomach ulcer (SU) is a disease of important medicalsocial value. According to the data of the World Health Organization, $10-15 \%$ of all the world's adult population suffer from stomach ulcers[1,2]. Moreover, according to the data of the Centre for Health Statistics, the morbidity rate to stomach and duodenal intestine ulcer (SDIU) has increased by $38.4 \%$ for the last 10 years in Ukraine. Thus, today, of more than 8151283 individuals suffering from digestive system diseases, $12.47 \%$ have stomach ulcers and $23.30 \%$ suffer from duodenal ulcers (DU). This means 2239.8 and 4186.5 patients per 100 thousand of population in Ukraine.

Successful anti-Helicobacter therapy of Hp-positive ulcers promotes a total recovery in $80-85 \%$ of all cases, as a rule, the frequency of ulcer relapses does not exceed $6 \%$ and the frequency of complications is only around 2-4\% [3]. Still, stomach ulcer is one of the leading reasons of productivity loss and development of disability [4].

According to data of the Centre for Statistics of the Ministry of Health of Ukraine, annually, almost 1 million of SU sick patients undergo follow-up care, each second patient passes treatment in the in-patient clinic, while more than a third of all sick patients use work incapacity certificates repeatedly. SU results in heavy complications (perforation, bleeding etc.) that are the reason for urgent surgical interferences in $25-30 \%$ of all cases [4].

The economical loss from SUDU almost to two times exceeds loss from cardiovascular pathology. Average annual charges to treatment of one SUDU patient in the USA amounts to $\$ 23819$, in Southern Korea - from 959.60 to $\$ 2553.10$. More than $\$ 750$ million per year are spent in the USA for treatment of SU patients with bleeding complications. Unfortunately, the data for Ukraine is not available as yet. The above-mentioned points to the necessity of treatment cost optimization of the disease and application of clinical and economical approaches to choosing the pharmacotherapy for the patients with the given pathology.

\section{MATERIAL AND METHODS}

In this study, 86 literary sources with evidence base of efficacy of proton pump inhibitors in the treatment of stomach ulcer and duodenal ulcer were used. The work was based on Best Evidence. Abstract and full-text medical databases, Internet-sources were mined. The methods used include descriptive, statistical and retrospective. Herein, descriptive research is used to describe characteristics of a population or phenomenon being studied. The statistical methods applied are mathematical formulas, models and techniques that are used in the statistical analysis of raw research data. The statistical methods were applied to extract information from research data and provide diverse ways of assessing the robustness of research outputs. The retrospective analysis or retrospective study is a research method that is used when the outcome of an event is already known. A retrospective study looks backwards and examines exposures to suspected risk or protection factors in relation to an outcome that is established at the start of the study.

\section{STUDY RESULTS AND DISCUSSION}

Currently, there are 6 groups of PPIs that are active pharmaceutical ingredients for the treatment of stomach ulcer and duodenal ulcer: Omeprazole (Omeprazole, Omez, Gasek, Ozolm), Lansoprazole (Lansoprazole, Lancerol, Lanza, Lanzoptol), Dexlansoprazole (Dexlansoprazole, Deksilant), Rabeprazole (Rabeprazole, Pariet, Rabimak, Barol), Pantoprazole (Pantoprazole, Kontrolok, Nolpaza, Proksium) and Esomeprazole (Esomeprazole, Neksium, Ezolong, Emanera, Ezomealoks, Ezera) [5].

Proton-pump inhibitors (PPIs) are a group of drugs, the main action of which is a pronounced and long-lasting reduction of stomach acid production. Proton pump inhibitors act by irreversibly blocking the hydrogen/potassium adenosine triphosphatase enzyme system (the $\mathrm{H}+$ / $\mathrm{K}+$ ATPase, or, more commonly, the gastric proton pump) of the gastric parietal cells. The proton pump is the terminal stage in gastric acid secretion, being directly responsible for secreting $\mathrm{H}+$ ions into the gastric lumen, making it an ideal target for inhibiting acid secretion.

The evaluation of the pharmacotherapy of SU from clinical and economical positions has become a subject of intensive research [6-11]. With the help of the pharmaco-economic method of "minimization of charges" worked out by. Germanuk et al. [12], the following parameters were defined: the most economically profitable tablets for SUDU treatment; economically profitable alternate layouts of antihelicobacter therapy (threefold therapy and fourfold therapy); and the number of sick patients who can be treated by the cheapest alternate layouts of threefold therapy and fourfold therapy comparatively to their more expensive variants[12].

In the work of Grushkovskaya [13], we can follow the results of comparative estimations of cost and curative efficiency of layouts of anti-helicobacter SUDU therapy. In his study, the author determined the optimum approach based on the criterion "expenditures-efficiency".

Using the pharmacoeconomic methods of "expenditures-efficiency" and "expenditures- utility" as proposed by Oisodlo et al. [10], we also determined the pharmacoeconomic advantages of new modes of anti-helicobacter therapy deemed sequential therapy and compared these to traditional layouts.

According to the results by Orlovsky et al. [14], "Barol" (Rabeprasol) as a part of anti-helicobacter therapy is faster and more effective than Omeprasolin and its use eliminates a clinical semiology of recrudescence of peptic ulcer of duodenal intestine, as well as congestion and oedema of the gastrointestinal mucosa. As a part of combined anti-helicobacter therapy, "Barol" (Rabeprasol) supplies high levels of $H$. pylori eradication (90.9\%) relatively to the layout in which Omeprasol (83.3\%) was used against a background of absence of clinically significant by-effects.

The prescription of Nolpaza (Pantoprasol) in the dose of $0.04 \mathrm{~g}$ two times per day positively affects all criteria of efficiency of ulcer suppressive therapy within anti-helicobacter treatment of patients with gastropathy. Furthermore, a seven-day layout of anti-helicobacter pharmacotherapy on the basis of Nolpaza $0.04 \mathrm{~g}$ two times per day, Clarythromycin $0.5 \mathrm{~g}$ two times a day and Amoxicillin $1.0 \mathrm{~g}$ two 
time/day can supply hyper-eradication in $96 \%$ of all patients with non-steroidal anti-inflammatory drugs gastropathy [13].

According to the data supplied by Scherbinina [15], the frequency of esophageal defects healing in four weeks was $14 \%$ in the placebo group, while the frequency of healing in four weeks administation of Nolpaza at a daily dose of $40 \mathrm{mg}$ accounted for $72 \%$. Moreover, the frequency of healing in 8 weeks was $88 \%$ [14].

In a study undertaken by Ilchenko et al. [16], of 50 patients with DU, the latent period, overall duration of drug effect, maximum time of drug effect, as well as the difference in intensity of anti-secretory action of the first taken dose of Ranitidin, Omeprasol, Rabeprasol were assessed. Accordingly, in 10 patients, the time of action of $20 \mathrm{mg}$ of Rabeprasol was 15.5 hours [16]. In addition, in other comparative research of PPI efficiency in the treatment of DU, on the $1^{\text {st }}$ day of treatment, $20 \mathrm{mg}$ of Rabeprasol $\mathrm{pH}>3$ accounted for $60.1 \pm 3.5$ of total effect. This was higher than that of the prescription drugs Ezomeprasol and Omeprasol [17].

Further research includes that of Wang Hand et al. [18] in which they compared the efficiency of Rabeprasol (10 mg two times/day) and Omeprasol (20 mg two times/ day) on the first day of administration [18], and that of Babak, who carried out a comparative evaluation of clinical efficiency of Rabeprasol and other inhibitors of proton pump by applying meta-analysis. Herein, the taking of $10 \mathrm{mg}$ of Rabeprasol on the $1^{\text {st }}$ day of treatment resulted in epigastric burning disappearing in more than $28 \%$ of all studied patients, and when up to the end of the 4 th and the $8^{\text {th }}$ weeks of therapy - in 83,5 and $98.2 \%$ of all cases, respectively. The mentioned symptom control against a background of daily taking of $20 \mathrm{mg}$ Ezomeprasol was noted only on the $5^{\text {th }}$ day. Furthermore, after 8 weeks of Rabeprasol therapy, the total number of refluxes per day with $\mathrm{pH}<4$ decreased from $19.1 \pm 2.7$ to $1.4 \pm 0.5(\mathrm{p}<0.05)$, and in groups of Ezomeprasol therapy - from $19.0 \pm 0.6$ to $3.0 \pm 0.01(\mathrm{p}<0.05)$ and from $19.2 \pm 0.6$ to $1.8 \pm 0.02(\mathrm{p}<0.05)$ respectively.

The clinical efficiency of $20 \mathrm{mg}$ Rabeprasol and $20 \mathrm{mg}$ Omeprasolin treatment of active duodenal ulcer was also studied in a European randomized multi-institutional doubleblind experiment in which 205 patients participated who were taking PPIs for 2 or 4 weeks. In the score of frequency and rate of pain attacks, Rabeprasol showed superiority over Omeprasol. In the study, statistically significant differences with regard to the given pain attacks was evident on the 4th week (there was no pain in $92 \%$ of all individuals for Rabeprasol, as compared to $83 \%$ for Omeprasol; $p=0.038$ ) [19].

Dashiyev et al. [20] carried out a comparative evaluation of the effect engendered by different inhibitors of proton pump (Omeprasol, Neksium and Kontrolok) in patients with SUDU. Herein, the evaluation of anti-helicobacter therapy efficiency was carried out as of 6-7 weeks post-treatment. Accordingly, frequency of by-effects development on the whole accounted for $40.2 \%$, but the differences between groups were not reliable. The most frequent by-effects of the therapy were bowel disorders (diarrhea) $-20.1 \%$ of all those studied and headache $-8.1 \%$ of the total. On the whole, the rating of threefold therapy efficiency was at $77.2 \%$
(Omeprazol - $80 \mathrm{mg}$ per day, Kontrolok - $80 \mathrm{mg}$ per day, Ezomeprazol - $80 \mathrm{mg}$ per day) [20].

Yastrebkova carried out a comparative clinical efficiency trial of Rabeprasol (Pariet) and Ezomeprazol (Neksium) in the treatment of acid-dependent diseases of the gastrointestinal tract. Accordingly, the duration of antisecretory action of Pariet on the 4th day of intake (18.3 \pm 1.3 hours) statistically exceeded such duration of Neksium $(14.1 \pm 1.1$ hours) $(\mathrm{p}<0.05)$. Moreover, percentage part of the day during which $\mathrm{pH}$ in the stomach remained was $>3$ and $>5$, in the group of sick patients who took Pariet (respectively, $83.2 \%$ and $56.3 \%$ ). This exceeded similar ratings in the group of patients who took Neksium (62.7\% and 36.2\%). While taking Pariet at the dose of $20 \mathrm{mg}$, the frequency of by-effects (headache, vertigo, diarrhea, nausea, skin rashes) was $2 \%$ (in 7 patients out of 360 ), in contrast, that of $20 \mathrm{mg}$ of Ezomeprazol (Neksium) was 15.3\% (in 38 patients out of 250). What is more, compared to Omeprazol, the healing of gastric ulcers after 4 weeks of Pantoprasolin uptake was higher (88 against 77\%). In addition, epigastric burning disappeared in patients of administered "Pulcet" (Group I) after $4.7 \pm 1.8$ days, and in patients administered Omeprazol (Group II) after $5.0 \pm 1.9$ days. Still, differences in speed of symptoms relief are doubtful $(\mathrm{P}>0.05)$. However, over-night epigastric burning at the beginning of treatment was observed in 3 patients of Group I $(9.75 \% \pm 5.3 \%)$ and in 7 of Group II $(22.5 \% \pm 7.5 \%)$. In addition, reflux esophagitis disappeared, according to control gastroscopy data in 27 patients of Group I $(87.1 \% \pm 6.0 \%)$, and the regress of esophagitis from degree B to degree A was observed in 4 patients. In Group II, the healing of gastrointestinal mucosa was noted in 20 patients $(64.5 \% \pm 8.4 \%)$, in $7-$ a regress from degree $\mathrm{B}$ to degree $\mathrm{A}$, in 4 - catastasis was not improved. Differences in frequency of esophagitis healing between groups are reliable $(\mathrm{P}<0.05)$. Clinically significant by-effects are not registered [20].

The eradication level with Kontrolok, as stated in the original researches by Kliarytska, ranged from 74.4\% up to $95.7 \%$. Herein, the lowest percent of eradication was at PPIs - threefold modes which contain Metronidazole (Kontrolok + Amoxicillin + Metronidazole - eradication at 37\%; Kontrolok + Metronidazole + Intetrics - eradication at $74.4 \%$; Omeprasol + Amoxicillin + Metronidazole - eradication at $46.7 \%$ ). The corresponding figures for quadruple therapy give an eradication level range of $93.75 \%$ to $95.7 \%$; at PPIs - threefold mode - 93\% [21].

The research undertaken by Vasilyev and Kasianenko of a test population of 19 patients that was based upon the quick urea test and 13C-urea breath test indicated that 4 weeks after the ending of a 7-day regimen of eradication therapy, total eradication HP was determined in all 19 patients $(100 \%)$; and per histologic research in 18 out of 19 patients $(94.7 \%)$ [22]. It should be noted that all by-effects were mild-to-moderate, nor was change of the regimen or cancellation of therapy needed.

\section{CONCLUSIONS}

In this study of current therapy, Omeprazol pills are not included because of proven greater efficiency of 
Ezomeprazol pills; while Lansoprazol pills are not included because of proven short acid-inhibitory effect (and the product is not sold in Ukraine), Rabeprazol pills are presented in the research as 'Pariet' (brand), as well as by the effective generic 'Barol'; Pantoprazol pills are presented in the research as 'Kontrolok' (brand) and Pantosan (brand), as well as by generics 'Pulcet' and 'Nolpasa' (herein, the effect of Pantosan is not different from the effect of Pulcet and Nolpaza, however, it is far more expensive); finally, Ezomeprazol pills are presented by brand pills of 'Neksium' and the generic 'Ezolong'.

The author concludes this work by stating that it is necessary to continue further multisite randomized comparative researches of clinical efficiency of other PPIs, as well as the evaluation of results.

\section{ORCID iDs}

Olesya Pavlivna Balitska

Tamara Andreevna Germanyuk

Dhttps://orcid.org/0000-0003-0990-7146

Yuliia Mykolaivna Hrygoruk

Dhttp://orcid.org/0000-0003-4939-5907

(D) https://orcid.org/0000-0002-9298-5550

Tatiana Ivanovna Ivko (Dhttps://orcid.org/0000-0003-2873-1473

Yuliia Oleksandrivna Tomashevska

Vasyl Mykolayovich Koval

Dhttps://orcid.org/0000-0001-9708-1887

Yuliia Mykolayina Polishchuk

(D) https://orcid.org/0000-0001-9324-209X

Viktoriia Volodymyrivna Hutsol

Dhttps://orcid.org/0000-0001-7671-2328

Myhailo Andriyovich Artemchuk

(D) https://orcid.org/0000-0003-1477-2186

(D)https://orcid.org/0000-0003-3680-8493

\section{REFERENCES}

1. Zaychenko AV, Bryukhanova TA. Innovative approaches to pharmacological correction of hypersecretory conditions. Pharm Weekly. 2012;43:864-7

2. Stepanov YM. Digestive diseases and gastroenterological help to the population of Ukraine: achievements, problems and ways of their solution. Health of Ukraine. 2014;3(33):10-1.

3. Morozov AM, Yakovleva LV, Bezditko NV, Mishchenko OY, Stepanenko AV, Zimenkovsky A B. Evaluation of the clinical and economic feasibility of the use of drugs in a healthcare institution (suport of the formular system): method. rivers. Kh. Style Publishing; 2013:36-8.

4. Yakovleva LV Gerasimova OO, Gorbacheva AS, Yakovleva LV. Clinical and economic aspects of pharmacotherapy of patients with peptic ulcer. Pharm J.2015; 3:83-7.

5. Germanyuk TA, Bobryuk VP, Balanchuk TI, Tikholaz SI. Modern Classifications of Essential Medicines: Educational Posinik. Vinnytsya: National Pirogov Memorial Medical University; 2018:126-8.
6. Sikal MO, Sikal MO. Application of X-ray and vascular hemostasis in the complex of surgical treatment of acute gastrointestinal bleeding of ulcerativegenesis. Kharkiv Surgical School. 2013;4(61):96-8.

7. Fomin PD, Nikishaev VI. Bleeding from the upper gastrointestinal tract: causes, risk factors, diagnosis, treatment. Health of Ukraine. 2010;2:8-11.

8. Lazebnik LB, Guseinzade LB, Efremov LI. Estimation of the total cost of inpatient treatment of duodenal ulcer associated with H. pylori. Qual Clin Practice. 2008;2:62-70.

9. Gerasimova OO, ZagrebelnaYM. Pharmacoeconomic analysis of different regimens of anti-helicobacter therapy of peptic ulcer and duodenum. Ration Pharmacother. 2010;4:32-6.

10. Oisodlo GV, Prokopchuk SM, Voitsekhovsky OM. Components of the effectiveness of anti-helicobacter therapy in H. Pylory-associated diseases of the digestive system. Health of Ukraine. 2014;2:31-2.

11. Solovyov OS, Gudzenko IO, Levchenko OP. Kozitska KI. Pharmacoeconomic evaluation of the use of proton pump inhibitors in the treatment of stomach ulcer. Ukrainian Medical Almanac. 2013;16(4):54-6.

12. Germanyuk TA, Dzyubenko SP. Research of the pharmaceutical market of anti-herbicacid preparations and analysis of minimization of expenses of anti-herbic bacterial therapy. Curr Issues Pharm Med Sci Prac. 2012;2:102-6.

13. Grushhkovskaya DT. Pharmacoeconomic aspects of medical provision of patients with peptic ulcer in the stomach and duodenum. Pharmaceut Mag. 2014;4:125-8.

14. Orlovsky VF, Orlovsky AV, Murenets NA. Clinical efficiency of rabeprazol in patients with peptic duodenal ulcer. Health Medic. 2008;3(119):67-9.

15. Scherbinina MB. Nolpaza - a promising proton pump inhibitor. Mod Gastroenterol. 2010;56(6):83-7.

16. Ilchenko AA. Computer pH-metry of the stomach and esophagus. The clinical significance of the method: Methodical recommendations. Moscow: Moscow City Health Department; 2001:40.

17. Ivashkin VT, Sheptulin AA, Makarov YS, Nemytin YV. Comparative evaluation of the antisecretory activity of the LAPM MAPS, pariet and nexium in patients with peptic ulcer. Clin Persp Gastroenterol Hepatol. 2002;5:19-22.

18. Wang H, Nie YQ, Dai SJ. The effect of proton pump inhibitor on intragastric acidity and it relation to S-mephenytoin hydroxylase genetic polymorphism. Zhonghua Nei Ke Za Zhi. 2003;42:777-80.

19. Babak OY. Comparative evaluation of the clinical efficacy of Rabeprazole and other proton pump inhibitors according to the results of a meta-analysis. Mod Gastroenterol. 2007;3(35):53-7.

20. Dashiyev TD, Plehanov AN, Tovarshinov AI. Comparative evaluation of the effect of various inhibitors of proton pump (omeprazole, nexium, control) in the treatment of patients with ulcers of the stomach and duodenum. [Electronic resource] http:// www.rusnauka.com/34_NIEK_2013/Medecine/6_148522.doc.htm

21. Peredery VG, Chernyavsky VV, Dudar LV. Experience with the use of the drug „Pultset” for the treatment of patients with gastroesophageal reflux disease. Mod Gastroenterol. 2010;2(52):70-3.

22. Vasilyev YuV, Kasyanenko VI. Efficienty of 1-week application of Ezomeprazol (Nexium), Claritromycine and Amoxicillin in the treatment of extractive disease associated with helicobacter pylory. Medicina svitu. 2004;3. [Electronic resource] http://msvitu.com/ archive/2004/march/article-10.php. 